\title{
DON SERGIO NO ES SÓLO \\ PATRIMONIO DE LA IGLESIA
}

Mario Rivas D.

Cuando se me solicitó escribir un artículo acerca de mi experiencia como laico trabajando junto a Monseñor Sergio Contreras supe inmediatamente que no seria una tarea fácil y no sólo por correr el riesgo de ser leido por él, sino también por las restricciones que implica elaborar en dos páginas una idea aproximada a la dimensión de la práctica que desarrolló Monseñor como pastor de la Diócesis San José de Temuco durante los 23 años que estuvo a su cargo.

Como primera idea debo decir que Monseñor nunca fue un Obispo bondadoso a la hora de aceptar la inconsecuencia o la falta de compromiso con los temas sociales, en este sentido creo que su gran tarea evangelizadora fue obligar a los laicos que trabajamos cercanos a él, de hacernos cargo y responsables de la realidad de nuestra Región y sus problemas emergentes.

En este mismo sentido, la labor de nuestro Obispo siempre fue un signo de los tiempos; la defensa de los derechos humanos cuando no existian las garantias minimas para su resguardo, la reconstrucción de la democracia cuando se inició la incipiente tarea de recuperarla, el acompañamiento al mundo indigena en su dignidad como pueblo, la acción profética frente a la inequidad y la exclusión social de los más pobres, el esfuerzo continuo por el derecho a la igualdad de oportunidades de las mujeres, la defensa de los trabajadores y el mundo sindical, fueron y son sus grandes preocupaciones en el Chile de hoy.

En reiteradas ocasiones lo acompañé en sus visitas a sectores rurales de nuestra Región, donde expresaba su capacidad de dialogar con los hombres y mujeres del mundo campesino e indigena. Este interés permanente de encontrarse con su pueblo, se relaciona con su preocupación por la vida cotidiana, en la dimensión terrenal del aqui y el ahora, en la vivencia de un Evangelio movilizador del hombre y la mujer en sus necesidades materiales y espirituales. El diálogo fue el camino buscado por Monseñor para el entendimiento en nuestra sociedad regional, como la mejor y en ocasiones la única alternativa contra la imposición de la violencia y la fuerza. 
En los tiempos dificiles, una conversacior cum el era un aliciente para vencer el miedo, muchas veces compartinos a angustia de conocer la verdad y la imposibilidar concrela de hacei algo con eila. En esos duros momentos, sólo resguardaron a Monseño la lie y la giación. Fueron tiempos muy dificiles y todos los laicos que lo acomiatianos en esta elapa de su misión pastoral aún sentimos que qucda uir gran camino para alcanzar la verdad y la justicia.

Es curioso pensar cóno un gran investigador y esfudioso de los temas sociales y pastorales, se haya constituido en Pastor, fundamentalmente en la vida cotioliana de su pueblo. Un dia bendiciendo a los pescadores de Nehuentue sobre un pequeno bote rocorriendo el rio Imperial, otro en una jornada con representanios del pueblo mapuche. animándolos en la defensa de su pueblo y de su cultura. o bien celebrando una Liturgia junto a los colonos de Lonquimay, que hacen soberania de un pais que muchas veces los ignora. Estos lugares formaron parte de su memoria, la que nos ha traspasado como deber y conpromiso

Creo que la Iglesia de Temuco, antos de la llegada de Monseñor Contreras, era una Iglesia preferenternente caterusta, al termino de su labor como Pastor, queda el desafio de concolidar la Iglesia quo recibió, pero también fortalecer la Iglesia que nos entrega, dondo la preccupación por los temas sociales tiene una parte impotane de la miston evangelizadora. En este campo, es donde hoy dia entrere una Iglesia Diocesana con un fuerte compromiso y capacidad laical.

El consolidar una Iglesia thas conomometide con ios problemas del hombre y la mujer es uir gran destir pata of mindo de los consagrados y los laicos de nuestra Región en general, Don Sergio nos deja un llamado y un mandato que nos obliga a sumarins es? este esfuerzo; a toda et Area Social de la Iglesia, al Clero, a las iniversidades especialmente la Catolica de Temuco, a las Comunidades Eclesiales de Base y a todas ias organizaciones, que de alguna mancra represcntan la oxpresión de la Sociedad Civil que tanto interés y apoyo, ecibieron del fastor.

Creo que este os ol momento de destacar la elacin permanente que tuvo Don Sergio con la mayoria de las Organizaciones wo Gubernamentales de la Novena Región " aunque a el no io gusto decirlo, muchas de ellas tuvieron su origen en su apoyo y animasion:

\section{1. ¿Cuáles son los signos que nos dogit Monsenor Sergio Contreras?}

El estilo y acogida de la Casá de jercicios: ron que la Casa do Ejercicios hoy es parte do la memoria colectiva de muestia Region. No ha habido autoridades regionales y del pais tambici, gue an hay pasado por esta casa; estoy cierto que inportantes decisiones paia apoyar la reconstrucción de la democracia se tomaron ahi Muchos dirigentes campesinos e indigenas también pasaron por eila jara formarse y soñar 
con la vida que esperaban. Fue un lugar de encuentro y expresión de la vida de la Sociedad Civil de la Región, cuando escaseaban los espacios para encontrase con libertad y confianza.

La Fiesta de San Pedro: No me cabe duda que para la gente de Nehuentue y para nuestro Obispo, fue la expresión de la tremenda admiración que sentian por San Pedro, sin embargo creo que para Don Sergio en particular, fue el espacio para rememorar su añorado Valparaiso, nunca hizo la distinción de lo que podria significar celebrar el San Pedro en un gran puerto o en una pequeña caleta de pescadores de nuestra Región.

Las Semanas Sociales: Estas han sido el instrumento de nuestra Iglesia Diocesana para dar a conocer su preocupación por los temas contingentes. Su realización a cargo del Area Social de la Diócesis de Temuco, ha permitido anualmente convocar a la comunidad regional a reflexionar y expresar su pensamiento, desde una perspectiva solidaria.

La celebración de $1^{\circ}$ de Mayo: El encuentro anual para conmemorar el $1^{\circ}$ de Mayo en la Parroquia Jesús Obrero, ha sido la expresión del interés de Monseñor por el mundo de los trabajadores. Esta actividad continúa siendo una de las pocas manifestaciones donde trabajadores, empresarios y el mundo público, se encuentran para conmemorar la dimensión del trabajo como parte de la vida de los hombres y las mujeres.

Consejo DAS actualmente Ilamado Consejo de Area Social: Esta ha sido la instancia donde Monseñor ha hecho práctica su preocupación social; en mis 18 años trabajando junto a él sólo faltó en una ocasión por motivo de su asistencia a la visita Ad limina. En esta instancia integrada por representantes de las instituciones del área social y los Decanos de nuestra Diócesis, se ha discutido en forma permanente los instrumentos para abordar de manera sistemática, profesional y responsable, los temas emergentes de nuestra región.

\section{2. ¿Cuáles fueron sus preocupaciones preferentes?}

El mundo indigena: Fue una preocupación y una ocupación permanente en su laboral pastoral. En la riqueza de sus discursos y sus cartas pastorales se refleja su modestia de acercarse a la temática indigena, desde el encuentro y el conocimiento reciproco, no desde el conflicto, si desde el respeto a su condición como pueblo y a su cultura.

La justicia: Como expresión del deber cristiano no como posibilidad, sino como mandato. La justicia con los más pobres, con los que sufren la inequidad, la justicia para los que no tienen acceso a la verdad. La justicia como expresión de la solidaridad. 
El mundo de la mujer: Su preocupacion por las inequidades y la falta de oportunidades que viven las mujeres se expreso en hechos tan concretos como su apoyo irrestricto a la Asociación de Empleadas de Casas Particulares, ANECAP, para fortalecer la organización y la defensa que éstas han hecho de las mujeres trabajadoras. Siempre tuvo también una relación preferencial con organizaciones civiles y gubernamentales relacionadas con el tema de la mujer.

El mundo de los campesinos y la ruralidad en general: La labor pastoral de Monseñor refleja una preocupación preferencial por el mundo de los campesinos y la ruralidad en general. La labor formativa que impulso de la organización campesina, es la expresión de su voluntad de relevar la condición rural de nuestra región y el derecho de los campesinos de defender la vida en el campo.

\section{3. ¿Cuál es nuestro desafio hoy?}

La tarea que nos deja Monsenor es amplia y compleja. pero tambièn hermosa y motivadora. Nuestro desafio como laicos que pertenecemos al Area Social de la Iglesia de Temuco es fortalecer la presencia viva de estos simbolos y preocupaciones. de la forma que nuestro Obispo nos enseñó: la búsqueda de la transformación permanente, para que nuestro trabajo siempre sea un signo de los tiempos.

Por este motivo creo que el Obispo Contreras no es sólo patrimonio de nuestra Iglesia. sino es una persona que pertenece a los hombres y mujeres de toda la Región. Como lglesia servidora de la humanidad. Monseñor nos llamó a los laicos a cumplir nuestra tarea evangelizadora sobre la base del diálogo y el respeto a todo el pueblo de Dios, valorando la diversidad como expresión de la riqueza cultural de nuestra Región. 